\title{
Piceatannol inhibits MMP-9-dependent invasion of tumor necrosis factor- $\alpha$-stimulated DU145 cells by suppressing the Akt-mediated nuclear factor-kB pathway
}

\author{
RAJAPAKSHA GENDARA PRASAD THARANGA JAYASOORIYA ${ }^{1 *}$, YONG-GAB LEE $^{2 *}$, \\ CHANG-HEE KANG ${ }^{1}$, KYOUNG-TAE LEE ${ }^{3}$, YUNG HYUN CHOI ${ }^{4}$, SUNG-YONG PARK ${ }^{5}$, \\ JAE-KWAN HWANG $^{6}$ and GI-YOUNG KIM ${ }^{1}$
}

\author{
${ }^{1}$ Laboratory of Immunobiology, Department of Marine Life Sciences, Jeju National University, Jeju 690-756; \\ ${ }^{2}$ Department of Biomaterials Science and Technology, Yonsei University, Seoul 120-749; \\ ${ }^{3}$ Laboratory of Natural Product Chemistry, Division of Wood Chemistry and Microbiology, Department of Forest Products, \\ Korea Forest Research Institute, Seoul 130-712; ${ }^{4}$ Department of Biochemistry, College of Oriental Medicine, \\ Dongeui University, Busan 614-051; ${ }^{5}$ OTTOGI Research Institute, OTTOGI Ltd., Gyeonggi-do 431-070; \\ ${ }^{6}$ Department of Biotechnology, College of Life Science and Biotechnology, \\ Yonsei University, Seoul 120-749, Republic of Korea
}

Received June 11, 2012; Accepted September 6, 2012

DOI: $10.3892 / \mathrm{ol} .2012 .968$

\begin{abstract}
Piceatannol has potent anti-inflammatory, immunomodulatory, anticancer and antiproliferative effects. However, little is known about the mechanism by which piceatannol inhibits invasion and metastasis. The aim of the current study was to investigate the effects of piceatannol on the expression of matrix metalloproteinase-9 (MMP-9) in DU145 human prostate cancer cells. The results revealed that MMP-9 activity was significantly increased in response to tumor necrosis factor- $\alpha$ (TNF- $\alpha$ ). However, treatment with piceatannol reversed TNF- $\alpha$ - and MMP-9-induced gelatin zymography and its gene expression. In addition, a Matrigel invasion assay determined that piceatannol reduces the TNF- $\alpha$-induced invasion of DU145 cells. Nuclear factor- $\kappa \mathrm{B}(\mathrm{NF}-\kappa \mathrm{B})$ is a significant transcription factor that regulates numerous genes involved in tumor cell invasion and metastasis. Therefore, whether piceatannol acts on $\mathrm{NF}-\kappa \mathrm{B}$ to regulate MMP-9 gene expression was analyzed. The
\end{abstract}

Correspondence to: Professor Jae-Kwan Hwang, Department of Biotechnology, College of Life Science and Biotechnology, Yonsei University, 50 Yonsei-ro, Seodaemun-gu, Seoul 120-749, Republic of Korea

E-mail: jkhwang@yonsei.ac.kr

Professor Gi-Young Kim, Laboratory of Immunobiology, Department of Marine Life Sciences, Jeju National University, Ara-1 dong, Jeju-si 690-756, Republic of Korea

E-mail: immunkim@jejunu.ac.kr

${ }^{*}$ Contributed equally

Key words: piceatannol, matrix metalloproteinase-9, nuclear factor- $\kappa \mathrm{B}$, tumor necrosis factor- $\alpha$, Akt results revealed that piceatannol attenuates MMP-9 gene expression via the suppression of $\mathrm{NF}-\kappa \mathrm{B}$ activity. Using a specific $\mathrm{NF}-\kappa \mathrm{B}$ inhibitor, pyrrolidine dithiocarbamate, it was confirmed that TNF- $\alpha$-induced MMP-9 gene expression is primarily regulated by $\mathrm{NF}-\kappa \mathrm{B}$ activation. Piceatannol inhibited $\mathrm{NF}-\kappa \mathrm{B}$ activity by suppressing nuclear translocation of the NF- $\mathrm{B}$ p65 and p50 subunits. Furthermore, TNF- $\alpha$-induced Akt phosphorylation was significantly downregulated in the presence of piceatannol. The Akt inhibitor LY294002 caused a significant decrease in TNF- $\alpha$-induced NF- $\kappa$ B activity and MMP-9 gene expression. Overall, these data suggest that piceatannol inhibits TNF- $\alpha$ induced invasion by suppression of MMP-9 activation via the Akt-mediated NF-kB pathway in DU145 prostate cancer cells.

\section{Introduction}

Matrix metalloproteinases (MMPs), a group of zinc-dependent endopeptidases, are involved in the degradation of the extracellular matrix (ECM) under normal physiological conditions and during the metastatic process (1). While MMP activity is normally tightly regulated, dysregulation of MMP activity has been linked to cancer progression and metastasis via the degradation of the basement membrane and the induction of angiogenesis (2). The degree of overexpression of certain MMPs has been noted to correlate with the stage of disease and/ or prognosis (3). The majority of MMPs are secreted as inactive zymogens that are activated extracellularly and their functions are tightly regulated by several mechanisms (4). MMP-9 is a key effector molecule that promotes tumor cell invasion through type-IV collagen degradation-dependent extracellular matrix remodeling (5). MMP-9 expression has been observed in tumors of various organs, including the prostate, bladder, brain, liver and pancreas (6). The growth and metastasis of prostate cancer, as well as other tumors, is dependent on the formation 
of new blood vessels from preexisting ones via angiogenesis. Growing evidence suggests that prostate cancer cells secrete high levels of growth factors and matrix-degrading proteases, thus allowing metastasis to distant organs, including the liver, lungs, spine, bladder, bone and lymph nodes (7). Therefore, targeting MMP-9 inhibition for treating prostate cancers is considered to be an effective strategy.

A previous study has shown that the nuclear factor $\kappa \mathrm{B}$ $(\mathrm{NF}-\kappa \mathrm{B})$ pathway tightly regulates MMP-9 expression in several types of cancer cells (8). NF- $\kappa \mathrm{B}$ is normally located in the cytoplasm as an inactive dimer. The activity of $\mathrm{NF}-\kappa \mathrm{B}$ is regulated by interaction with inhibitory $\mathrm{I} \kappa \mathrm{B}$ proteins, which repress the potential of $\mathrm{NF}-\kappa \mathrm{B}$ to translocate to the nucleus and bind with DNA (9). Upon activation, I $\kappa \mathrm{B}$ is phosphorylated, which marks the inhibitor for ubiquitination and degradation via a proteasome-dependent pathway (10). A previous study demonstrated that the inhibition of $\mathrm{NF}-\kappa \mathrm{B}$ activity in human prostate cancer cells decreases their tumorigenic and metastatic abilities by suppressing angiogenesis and invasion via the downregulation of MMP-9 (11). Conversely, TNF- $\alpha$ stimulation results in $\mathrm{NF}-\kappa \mathrm{B}$ activation in prostate cancer cells and induces tumor invasion (12). Therefore, a potential strategy to suppress MMP-9-mediated tumor invasion is via the $\mathrm{NF}-\kappa \mathrm{B}$ pathway.

Piceatannol (3,5,3',4'-tetrahydroxytrans-stilbene), a phenolic compound and an analog of resveratrol, which naturally occurs in grapes and red wine, has been shown to possess anticancer properties via reduction in the expression of the anti-apoptotic protein Bcl-2 and inhibitors of apoptosis (IAP) family, in addition to anti-inflammatory activity via the downregulation of $\mathrm{NF}-\kappa \mathrm{B}$ (13-15). In a previous study, Kang et al reported the mechanism of piceatannol in terms of tumor necrosis factor-related apoptosis-inducing ligand (TRAIL)-induced apoptosis (16). However, the effects of piceatannol on MMP-9 gene expression and invasion in cancer cells have not been evaluated.

The current study examined the effects of piceatannol on MMP-9 expression and invasion in TNF- $\alpha$-stimulated DU145 prostate cancer cells. It was demonstrated that piceatannol downregulates TNF- $\alpha$-induced MMP-9 mRNA and protein expression by suppressing $\mathrm{NF}-\kappa \mathrm{B}$ activation. Furthermore, the regulation of NF- $\mathrm{NB}$ activity by piceatannol is associated with the inhibition of the phosphorylation of Akt.

\section{Materials and methods}

Reagent and antibodies. Piceatannol was purchased from Tocris (St. Louis, MO, USA) and dissolved in DMSO (vehicle). Antibodies against p65, p50, $\beta$-actin, phospho (p)-Akt and Akt were purchased from Santa Cruz Biotechnology (Santa Cruz, CA, USA). A specific NF- $\mathrm{NB}$ inhibitor pyrrolidine dithiocarbamate (PDTC) and a specific Akt inhibitor LY294002 were purchased from Calbiochem (San Diego, CA, USA). MMP-9 inhibitor I was obtained from Merck (Darmstadt, Germany). 3-(4,5-dimethyl-2-thiazolyl)-2,5-diphenyl-2H-tetrazolium bromide (MTT) and propidium iodine (PI) were obtained from Sigma (St. Louis, MO, USA).

Cell culture and viability. Human prostate cancer DU145 cells were obtained from the American Type Culture Collection
(Manassas, VA, USA). Cells were maintained in DMEM (WelGENE, Inc., Daegu, Korea) supplemented with $10 \%$ heat-inactivated FBS (WelGENE, Inc.) and $1 \%$ penicillinstreptomycin (WelGENE, Inc.) in $5 \% \mathrm{CO}_{2}$ at $37^{\circ} \mathrm{C}$. Cells were seeded at $1 \times 10^{5}$ cells $/ \mathrm{ml}$ and treated with the indicated concentrations of piceatannol. Following a 24-h incubation, the viability was determined by an MTT assay.

Flow cytometric analysis. Cell cycle distribution was analyzed by PI-stained cells. Briefly, cells $\left(1 \times 10^{6}\right)$ were fixed in $70 \%$ ethanol overnight at $4^{\circ} \mathrm{C}$. The cells were washed in phosphate-buffered saline (PBS) with $0.1 \%$ BSA. Cells were incubated with $1 \mathrm{U} / \mathrm{ml}$ RNase A (DNase free, Sigma) and $10 \mu \mathrm{g} / \mathrm{ml}$ PI overnight at room temperature in the dark. Cells were analyzed using a FACS Calibur flow cytometer (Becton Dickenson, San Jose, CA, USA). The levels of apoptotic cells with sub-G1 DNA were determined as a percentage of the total number of cells.

DNA fragmentation assay. Cells were treated with the indicated chemicals and then lysed on ice in a buffer containing $10 \mathrm{mM}$ Tris- $\mathrm{HCl}$ (pH 7.4), $150 \mathrm{mM} \mathrm{NaCl}, 5 \mathrm{mM}$ EDTA and $0.5 \%$ Triton X-100 for $30 \mathrm{~min}$. Lysates were vortexed and cleared by centrifugation at $10,000 \mathrm{x} g$ for $20 \mathrm{~min}$. Fragmented DNA in the supernatant was extracted with an equal volume of neutral phenol:chloroform:isoamylalcohol (25:24:1, v/v/v) and analyzed electrophoretically on a $1.5 \%$ agarose gel containing ethidium bromide.

Wound-healing assay. DU145 cells were grown to $90 \%$ confluence in a 6 -well plate at $37^{\circ} \mathrm{C}$ in a $5 \% \mathrm{CO}_{2}$ incubator. A wound was created by scratching cells with a sterile $200-\mu 1$ pipette tip, cells were washed twice with PBS to remove floating cells and then added to a medium without serum. Images of the wound were captured under an x100 magnitude microscope.

Gelatin zymography. Cultured DU145 cells were harvested and washed with serum-free DMEM three times and incubated for $24 \mathrm{~h}$ at $5 \times 10^{5}$ cells $/ \mathrm{ml}$ of serum-free DMEM. The cells were stimulated with piceatannol in the presence of TNF- $\alpha$ (20 ng/ml). MMP-9 activity was determined by gelatin zymography using $0.1 \%$ gelatin as a substrate. The conditioned medium was mixed with SDS-PAGE sample buffer in the absence of reducing agent and electrophoresed in $8 \%$ polyacrylamide gel. Following electrophoresis, the gels were washed three times with $2.5 \%$ Triton $\mathrm{X}-100$ in water and then incubated overnight in a closed container at $37^{\circ} \mathrm{C}$ in $0.2 \%$ Brij $35.5 \mathrm{mM} \mathrm{CaCl}_{2}, 1 \mathrm{mM} \mathrm{NaCl}$ and $50 \mathrm{mM}$ Tris, $\mathrm{pH}$ 7.4. The gels were stained for 30 min with $0.25 \%$ Coomassie Blue R-250 in $10 \%$ acetic acid and $45 \%$ methanol and then destained for 30 min using an aqueous mix of 20\% acetic acid, $20 \%$ methanol and $17 \%$ ethanol. Areas of protease activity appeared as clear bands.

RNA extraction and RT-PCR. Total RNA was isolated using TRIzol reagent (GIBCO-BRL, Gaithersburg, MD, USA) according to the manufacturer's recommendations. Genes of interest were amplified from cDNA that was reverse-transcribed from $1 \mu \mathrm{g}$ of total RNA using the One-Step RT-PCR Premix (iNtRON Biotechnology, Sungnam, Korea). Primers for 
MMP-9 sense (5'-CCTGGAGACCTGAGAACCAATCT-3') and antisense (5'-CCACCCGAGTGTAACCATAGC-3') and glyceraldehyde-3-phosphate dehydrogenase (GAPDH) sense (5'-CCACCCATGGCAAATTCCATGGCA-3') and antisense (5'-TCTAGACGGCAGGTCAGGTCCACC-3') were used. The PCR was initiated at $94^{\circ} \mathrm{C}$ for 2 min followed by 31 cycles of $94^{\circ} \mathrm{C}$ for $30 \mathrm{~min}, 30-\mathrm{min}$ annealing temperature, $72^{\circ} \mathrm{C}$ for $30 \mathrm{~min}$ followed by final extension at $72^{\circ} \mathrm{C}$ for $5 \mathrm{~min}$. The annealing temperatures for MMP-9 and GAPDH were $63^{\circ} \mathrm{C}$ and $62^{\circ} \mathrm{C}$, respectively. Following amplification, PCR products were separated on $1.5 \%$ agarose gels and visualized by ethidium bromide fluorescence.

Invasion assay. Cells (5x10 /chamber) were used for each invasion assy. Invasion assays were performed using modified Boyden chambers with polycarbonate nucleopore membrane (Corning, Corning, NY, USA). Precoated filters $(6.5 \mathrm{~mm}$ in diameter, $8 \mu \mathrm{m}$ pore-size, Matrigel $100 \mu \mathrm{g} / \mathrm{cm}^{2}$ ) were rehydrated and $5 \times 10^{4}$ cells in medium with or without piceatannol or MMP-9 inhibitor I (5 $\mathrm{nM})$ in the presence of TNF- $\alpha$ were seeded into the upper part of each chamber. Following $24 \mathrm{~h}$ incubation, nonmigratory cells on the upper surface of the filter were wiped with a cotton swab and migrated cells on the lower surface of the filter were fixed and stained with $0.125 \%$ Commassie Blue in a methanol:acetic acid:water mixture $(45: 10: 45, \mathrm{v} / \mathrm{v} / \mathrm{v})$. Random fields were counted under a light microscope.

Luciferase assay. NF- $\mathrm{\kappa B}$ reporter construct was purchased from Clonetech (Palo Alto, CA, USA) and MMP-9 promoter was obtained from Professor Y.H. Choi (Oriental Medicine, Dongeui University, Busan, Korea). Briefly, DU145 cells were plated onto six-well plates at a density of $5 \times 10^{5}$ cells/well and grown overnight. Cells were transfected with $2 \mu \mathrm{g}$ of each plasmid construct for $6 \mathrm{~h}$ by the Lipofectamine method. Following transfection, the cells were cultured in $10 \%$ FBS containing DMEM with the indicated concentrations of piceatannol in the presence of $20 \mathrm{ng} / \mathrm{ml} \mathrm{TNF}-\alpha$ for $24 \mathrm{~h}$. Cells were lysed with lysis buffer $(20 \mathrm{mM}$ Tris- $\mathrm{HCl}, \mathrm{pH} 7.8,1 \%$ Triton X-100, $150 \mathrm{mM} \mathrm{NaCl}$ and $2 \mathrm{mM}$ DTT). The cell lysate $(5 \mu \mathrm{l})$ was mixed with luciferase activity assay reagent $(25 \mu \mathrm{l})$ and luminescence produced for $5 \mathrm{sec}$ was measured using GLOMAX luminometer (Promega, Madison, WI, USA).

Electrophoretic mobility shift assay (EMSA). The preparation of cytoplasmic and nuclear extracts was conducted using the NE-PER nuclear and cytoplasmic extraction reagents (Pierce, Rockford, IL, USA). DNA-protein binding assays were carried out with nuclear extract. Synthetic complementary NF- $\kappa B$-binding oligonucleotides (5'-AGTTGAGGGGACTTTCCCAGGC-30'; Santa Cruz Biotechnology) were biotinylated using the biotin 30-end DNA labeling kit (Pierce) according to the manufacturer's instructions and annealed for $1 \mathrm{~h}$ at room temperature. Binding reactions were carried out for $20 \mathrm{~min}$ at room temperature in the presence of $50 \mathrm{ng} / \mathrm{ml}$ poly $(\mathrm{dI}-\mathrm{dC}), 0.05 \%$ Nonidet P-40, $5 \mathrm{mM} \mathrm{MgCl}_{2}, 10 \mathrm{mM}$ EDTA and 2.5\% glycerol in $1 \mathrm{X}$ binding buffer (LightShift ${ }^{\mathrm{TM}}$ chemiluminescent EMSA kit) with $20 \mathrm{fmol}$ of biotin-end-labeled target DNA and $10 \mu \mathrm{g}$ of nuclear extract. Assays were loaded onto native $4 \%$ poly- acrylamide gels pre-electrophoresed for $60 \mathrm{~min}$ in $0.5 \mathrm{X}$ Tris borate/EDTA and transferred onto a positively charged nylon membrane (HybondTM-N+) in 0.5X Tris borate/EDTA at $100 \mathrm{~V}$ for $30 \mathrm{~min}$. Transferred DNAs were cross-linked to the membrane at $120 \mathrm{~mJ} / \mathrm{cm}^{2}$ and detected using horseradish peroxidase-conjugated streptavidin according to the manufacturer's instructions.

Western blot analysis. Total cell extracts were prepared using PRO-PREP protein extraction solution (iNtRON Biotechnology). Proteins were separated by SDS-PAGE and electrotransferred to nitrocellulose membranes (Amersham, Arlington Heights, IL, USA). The detection of specific proteins was carried out with an ECL western blotting kit (Amersham) according to the manufacturer's instructions.

Statistical analysis. All data were derived from at least three independent experiments. The images were visualized with Chemi-Smart 2000 (Vilber Lourmat, Cedex, France). Images were captured using Chemi-Capt (Vilber Lourmat) and transported into Adobe Photoshop (version 8.0). All data are presented as mean \pm SE. Significant differences between the groups were determined using one-way ANOVA test. $\mathrm{P}<0.05$ was considered to indicate a statistically significant difference.

\section{Results}

Piceatannol does not affect DU145 cell viability. In order to determine the cytotoxic potential of piceatannol on DU145 cells, an MTT assay was performed at $24 \mathrm{~h}$ following treatment with various concentrations $(0-40 \mu \mathrm{M})$ of piceatannol in the presence or absence of TNF- $\alpha$, regardless of the presence of FBS. Piceatannol alone, or in conjunction with TNF- $\alpha$, was not cytotoxic at any of the concentrations tested in this study (Fig. 1A). Therefore, piceatannol levels of $<40 \mu \mathrm{M}$ were selected for subsequent experiments. Subsequently, the effect of piceatannol on cell viability and cytotoxicity was analyzed in detail. According to the percentages of sub- $\mathrm{G}_{1}$ DNA content as measured by flow cytometry, no apoptotic cell death was observed compared with the positive $\mathrm{H}_{2} \mathrm{O}_{2}$-treated group (Fig. 1B). Furthermore, DNA fragmentation was analyzed to determine the level of fragmented DNA. No fragmented DNA was identified in the piceatannol alone or the TNF- $\alpha$ treated groups compared with the positive $\mathrm{H}_{2} \mathrm{O}_{2}$-treated group (Fig. C). To determine whether piceatannol also inhibited TNF- $\alpha$-induced migration, a scratch wound healing assay was performed. Cell migration was significantly increased by TNF- $\alpha$ treatment and was inhibited by the presence of piceatannol (Fig. 1D). Overall, these data indicate that piceatannol inhibited TNF- $\alpha$-induced migration, and hence tumor invasion, without any cytotoxicity.

Piceatannol inhibits TNF- $\alpha$-induced invasion of DU145 cells by suppressing MMP-9 activation. Zymography, RT-PCR and measurement of luciferase reporter activity were conducted to assess whether piceatannol regulates TNF- $\alpha$ induced MMP-9 expression. The zymography data revealed that the secretion of MMP-9 was significantly increased by TNF- $\alpha$ treatment compared with the untreated control group. 
A
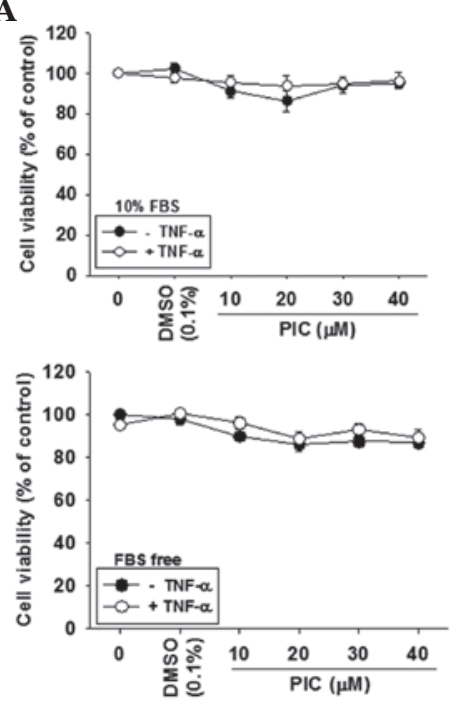

B

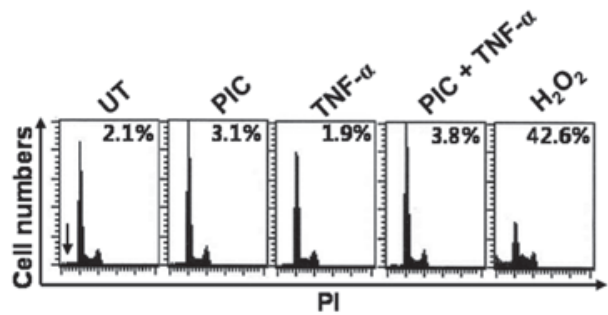

C

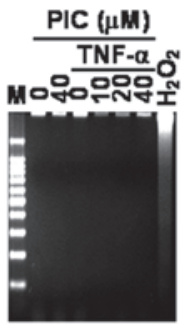

D

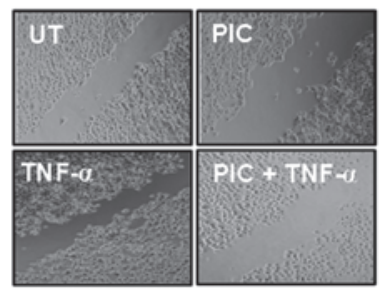

Figure 1. Effects of PIC on the viability of DU145 cells. DU145 cells treated with the indicated concentrations of PIC and/or 20 ng/ml TNF- $\alpha$ in the presence (upper panel) or absence of serum (lower panel) for $24 \mathrm{~h}$. (A) Cell viability was measured by an MTT assay following $24 \mathrm{~h}$. (B) DNA content was analyzed by flow cytometry. Percentages of sub- $\mathrm{G}_{1}$ DNA content are represented in each panel. The data and arrow in the figure represent the percentage of each sub- $\mathrm{G}_{1}$ phase in cell cycle distribution. (C) Total DNA was extracted from the treated cells and the DNA fragmentation assay analyzed on a 1.5\% agarose gel. (D) For the wound healing assay, cells were treated with PIC and/or PIC/TNF- $\alpha$ in a 6 -well plate and incubated for $24 \mathrm{~h}$. Images of the wound were captured under x100 magnifications using a microscope. Data from 3 independent experiments are expressed as overall mean \pm SE. Statistical significance was determined by one-way ANOVA test ( ${ }^{\mathrm{P}}<0.05$ vs. untreated control). PIC, piceatannol; TNF- $\alpha$, tumor necrosis factor- $\alpha$; UT, untreated.

Piceatannol decreased TNF- $\alpha$-induced MMP-9 activity in a dose-dependent manner (Fig. 2A). In a subsequent experiment, the luciferase activity of MMP-9 was assayed using transient transfection with reporter vectors that included MMP-9 promoters. Treatment with TNF- $\alpha$ significantly increased MMP-9 luciferase activity, whereas piceatannol downregulated TNF- $\alpha$-induced MMP-9 luciferase reporter activity (Fig. 2B). In addition, RT-PCR analysis revealed that steady-state MMP-9 mRNA levels are undetectable in piceatannol-treated cells compared with the untreated control group (Fig. 2C). TNF- $\alpha$ stimulation of cells resulted in a significant increase in MMP-9 mRNA expression compared with the untreated control; however, piceatannol completely reversed TNF- $\alpha$-induced MMP-9 mRNA levels to the levels of the untreated control. Since MMP-9 is thought to be critically involved in the processes of tumor invasion (25), the effects of piceatannol on the invasion of DU145 cells was examined. In the invasion assay, when the cells were treated with TNF- $\alpha$ alone, a marked 4-fold increase in cell invasion was observed compared with the untreated control. However, the addition of piceatannol resulted in an $\sim 50 \%$ reduction in penetration through a Matrigel-coated membrane when compared with the TNF- $\alpha$-treated group (Fig. 2D). Addition of MMP-9 inhibitor I significantly blocked TNF- $\alpha$-induced cell invasion. These results confirm that piceatannol suppressed the upregulation of TNF- $\alpha$-stimulated MMP-9 expression at the transcription level and inhibited TNF- $\alpha$-induced invasion of DU145 carcinoma cells.

Piceatannol inhibits TNF- $\alpha$-induced expression of the $M M P-9$ gene by suppression of $N F-\kappa B$ activity. In order to determine whether MMP-9 mRNA expression was linked to $\mathrm{NF}-\kappa \mathrm{B}$ activity, a promoter assay was conducted using DU145 cells that had been transiently transfected with a luciferase reporter vector, which included the $\mathrm{NF}-\kappa \mathrm{B}$-binding sites. NF- $\kappa \mathrm{B}$ luciferase activity was significantly increased, $\sim 7.4$-fold, in TNF- $\alpha$-stimulated DU145 cells compared with the untreated control group (Fig. 3A). However, the TNF- $\alpha$-stimulated luciferase activity in the cells containing the $\mathrm{NF}-\kappa \mathrm{B}$ construct was significantly reduced to $\sim 50 \%$, by treatment with piceatannol. An EMSA was conducted to evaluate the effect of piceatannol on the DNA-binding activity of $\mathrm{NF}-\kappa \mathrm{B}$ to assess its inhibitory effect on the transcriptional activity of MMP-9. Nuclear extracts from control and piceatannol-treated DU145 cells were subjected to analysis for the DNA-binding activity of NF- $\kappa \mathrm{B}$. This reached a maximum at $30 \mathrm{~min}$ and was sustained for $1 \mathrm{~h}$ following treatment with TNF- $\alpha$ (data not shown). EMSA data revealed that treatment with piceatannol downregulated the TNF- $\alpha$-induced DNA-binding activity of NF- $\kappa \mathrm{B}$ at $30 \mathrm{~min}$ (Fig. 3B). As shown in the western blot analysis, treatment with TNF- $\alpha$ decreased the levels of p65 and p50 in the cytosolic extract, whereas the addition of piceatannol resulted in sustainment of the levels of p65 and p50. This suggests that piceatannol inhibits the nuclear translocation of $\mathrm{NF}-\kappa \mathrm{B}$ subunits p65 and p50 (Fig. 3C). In addition, our data indirectly demonstrated that a specific NF- $\kappa \mathrm{B}$ inhibitor PDTC has the ability to inhibit TNF- $\alpha$-induced expression of MMP-9 mRNA (Fig. 3D). These results indicate that treatment with piceatannol suppresses MMP-9 gene expression in TNF- $\alpha$-induced DU145 cells via inhibition of NF- $\kappa$ B activity.

Piceatannol downregulates Akt phosphorylation, which regulates $N F-\kappa B$-dependent MMP-9 gene expression. As Akt is known to be an upstream regulator of $\mathrm{NF}-\kappa \mathrm{B}$, we investigated whether $\mathrm{NF}-\kappa \mathrm{B}$ activity is regulated by piceatannol-induced Akt phosphorylation or dephosphorylation. Western blot analysis revealed that TNF- $\alpha$ stimulation induced the 
A

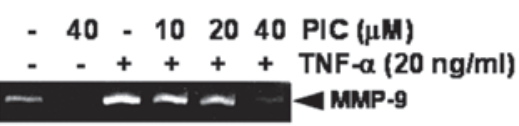

C $\quad-40-102040 \mathrm{PIC}(\mu \mathrm{M})$

$-++++\operatorname{TNF}-\alpha(20 \mathrm{ng} / \mathrm{ml})$

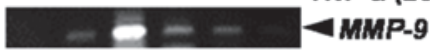

$-\infty-\infty-\infty G A P D H$

D

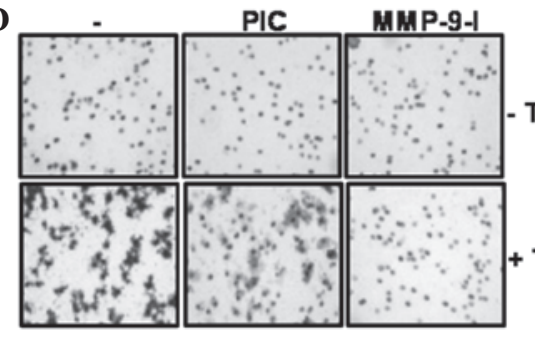

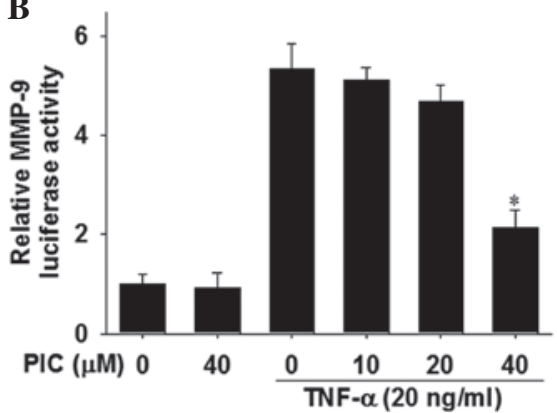

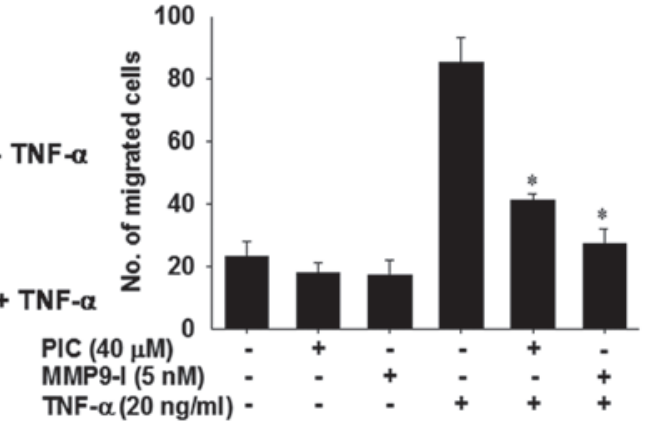

Figure 2. Effects of PIC on MMP-9 activity and invasion. DU145 cells were treated with various concentrations of PIC in the presence of TNF- $\alpha$ (20 ng/ $\mathrm{ml}$ ). (A) Conditioned medium was collected from cultures following $24 \mathrm{~h}$ and analyzed by gelatin zymography. (B) In a parallel experiment, DU145 cells were transfected with a WT-MMP-9 promoter-containing reporter vector and luciferase activity was measured $24 \mathrm{~h}$ following transfection. (C) Total RNA was isolated and RT-PCR analysis was performed. (D) For the invasion assay, the lower and upper parts of the Transwells were coated with Matrigel. DU145 cells were cultured with PIC or MMP-9 inhibitor I (MMP-9-I; $5 \mathrm{nM}$ ) in the presence or absence of TNF- $\alpha$. Invasiveness of the cells was determined by measuring their ability to pass through a layer of a Matrigel-coated filter. Following $24 \mathrm{~h}$, cells on the bottom side of the filter were fixed, stained and counted as described in Materials and methods. Data from 3 independent experiments are expressed as overall mean \pm SE. Statistical significance was determined by one-way ANOVA test ("P $<0.05$ vs. TNF- $\alpha$-treated group). PIC, piceatannol; TNF- $\alpha$, tumor necrosis factor- $\alpha$; MMP, matrix metalloproteinase; GAPDH, glyceraldehyde-3-phosphate dehydrogenase.

A

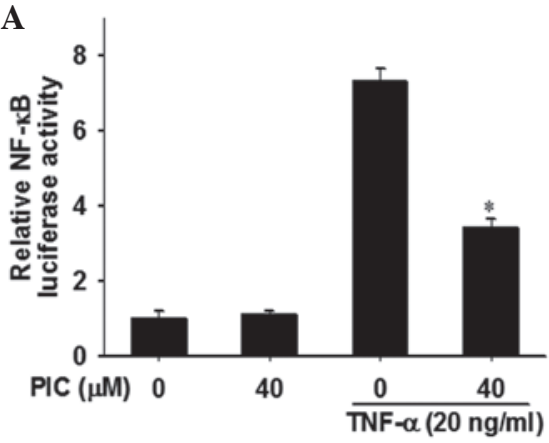

C

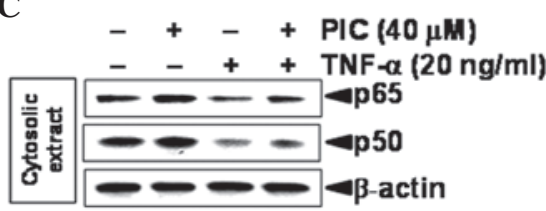

B

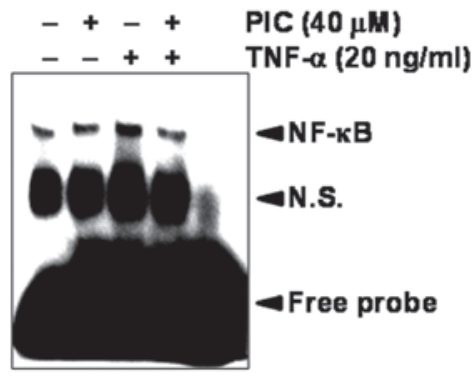

D

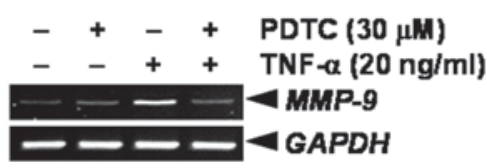

Figure 3. Effects of PIC on NF-kB-dependent MMP-9 regulation. DU145 cells were treated with $40 \mu \mathrm{M}$ PIC in the presence of TNF- $\alpha$ (20 ng/ml). (A) Cells were transfected with an NF-kB promoter-containing reporter vector and luciferase activity was measured $24 \mathrm{~h}$ following transfection. (B) The nuclear extracts were prepared at $30 \mathrm{~min}$ and the EMSA measured NF- $\mathrm{kB}$ binding to its DNA promoter region in the extract. (C) The cytosolic extracts were prepared to

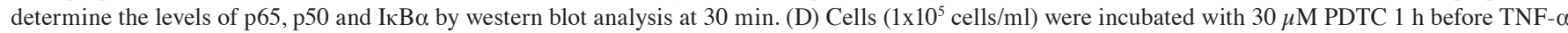
$(20 \mathrm{ng} / \mathrm{ml}$ ) treatment for $18 \mathrm{~h}$. Total RNA was isolated and RT-PCR analysis of MMP-9 was performed. GAPDH was used as an internal control for RT-PCR. Data from 3 independent experiments are expressed as overall mean \pm SE. Statistical significance was determined by one-way ANOVA test ("P $<0.05$ vs. TNF- $\alpha$-treated group). PIC, piceatannol; NF- $\mathrm{KB}$, nuclear factor- $\mathrm{kB}$; TNF- $\alpha$, tumor necrosis factor- $\alpha$; EMSA, electrophoretic mobility shift assay; PDTC, pyrrolidine dithiocarbamate; MMP, matrix metalloproteinase; GAPDH, glyceraldehyde-3-phosphate dehydrogenase.

phosphorylation of Akt at 15 min, whereas treatment with piceatannol suppressed the phosphorylation of Akt (Ser 473, Fig. 4A). It was also demonstrated that a specific Akt inhibitor
LY294002 completely eliminated the TNF- $\alpha$-induced NF- $\kappa$ B promoter activity, suggesting that inactivation of Akt by piceatannol regulates TNF- $\alpha$-induced NF- $\mathrm{B}$ (Fig. 4B). 
A

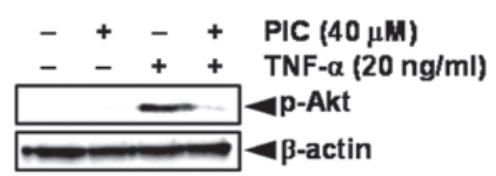

C

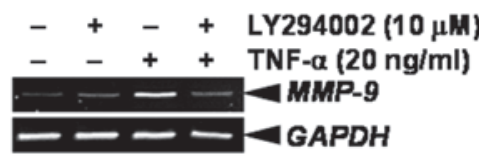

B

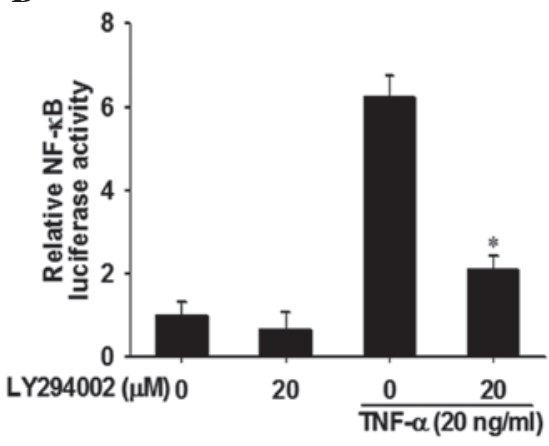

Figure 4. Effects of PIC on Akt phosphorylation. (A) Cells were pretreated with $40 \mu \mathrm{M}$ PIC $1 \mathrm{~h}$ before stimulation with $20 \mathrm{ng} / \mathrm{ml} \mathrm{TNF}-\alpha$ for $15 \mathrm{~min}$. Western blot analysis was performed to determine Akt phosphorylation. (B) Cells were transfected with a NF- $\mathrm{kB}$ promoter-containing reporter vector and luciferase activity was measured $24 \mathrm{~h}$ following transfection. (C) Cells ( $1 \times 10^{5}$ cells $\left./ \mathrm{ml}\right)$ were incubated with $10 \mu \mathrm{M} \mathrm{LY} 2940021 \mathrm{~h}$ before TNF- $\alpha(20 \mathrm{ng} / \mathrm{ml})$ treatment for $18 \mathrm{~h}$. Total RNA was isolated and RT-PCR analyses of MMP-9 were performed. GAPDH was used as an internal control for RT-PCR. Data from 3 independent experiments are expressed as overall mean \pm SE. Statistical significance was determined by one-way ANOVA test $\left({ }^{*} \mathrm{P}<0.05\right.$ vs. TNF- $\alpha$-treated group). PIC, piceatannol; TNF- $\alpha$, tumor necrosis factor- $\alpha$; MMP, matrix metalloproteinase; GAPDH, glyceraldehyde-3-phosphate dehydrogenase; NF- $\kappa \mathrm{B}$, nuclear factor- $\kappa \mathrm{B}$.

Moreover, RT-PCR analysis demonstrated that pretreatment of DU145 cells with LY294002 suppressed TNF- $\alpha$-induced MMP-9 activity at the transcription level (Fig. 4C). These results confirmed that piceatannol regulated TNF- $\alpha$-induced MMP-9 gene expression by blocking Akt phosphorylation-dependent NF- $\kappa \mathrm{B}$ activity.

\section{Discussion}

Our previous study determined that piceatannol considerably suppresses lipopolysaccharide-induced pro-inflammatory cytokines and nitric oxide expression in BV2 microglial cells (15). Furthermore, it has been reported that piceatannol enhances TRAIL-induced apoptosis in human leukemia THP-1 cells via Sp1- and ERK-dependent DR5 upregulation (16). It is not fully known how piceatannol regulates anticancer activity during the invasion process. Therefore, we investigated whether piceatannol inhibits TNF- $\alpha$-induced MMP-9, leading to decreased invasion of DU145 prostate cancer cells, by suppression of NF- $\mathrm{kB}$ activity. This study provides substantial evidence that piceatannol inhibits TNF- $\alpha$-induced MMP-9 expression in DU145 prostate cancer cells by suppressing Akt-mediated NF- $\kappa B$ activity.

MMPs are capable of digesting various components of the extracellular matrix and other molecules, including cell surface receptors, growth factors and cell adhesion molecules $(17,18)$. Thus, they play a significant role in tissue repair, tumor invasion and metastasis $(19,20)$. The generation and analysis of transgenic and knockout mice for MMPs have confirmed that MMPs play key roles in the process of carcinogenesis and invasion (21). One of these, MMP-9, is regarded as a critical molecule in tumor progression and invasion (22). Therefore, inhibition of MMP-9 appears to be an ideal strategy to control tumor growth, invasion and metastasis. Our results demonstrate that piceatannol inhibits TNF- $\alpha$-induced MMP-9 activity accompanied by the suppression of MMP-9 gene transcription in DU145 prostate cancer cells. Notably, the Matrigel assay revealed that piceatannol significantly suppresses cell invasion when compared with an MMP-9 inhibitor. Previous studies have also identified the signal transduction pathways involved in regulating MMP-9 expression in various tumor cells $(23,24)$. In particular, NF- $\kappa B$ is a significant transcription factor for regulating the MMP-9 gene promoter and contains NF-kB-binding sites (12). This study revealed that piceatannol regulates NF- $\mathrm{KB}$ activity by inhibiting p65 and p50 protein translocation. The results of the current study suggest that the downregulation of NF- $\mathrm{KB}$ by piceatannol potentiates antitumor and antimetastatic activities via the downregulation of MMP-9 expression. A previous study has illustrated that the suppression of NF- $\mathrm{kB}$ activity in human prostate cancer cells inhibits their tumorigenic and metastatic properties in nude mice by suppressing angiogenesis and invasion via the downregulation of MMP-9 (25). It has also been reported that several transcription factors in the human MMP-9 promoter region, including AP-1 and Sp1, regulate MMP-9 expression in response to PMA and TNF- $\alpha$ induction $(26,27)$. Therefore, further studies are required to determine whether other transcriptional factors are inhibited in piceatannol-induced MMP-9 downregulation. In addition, we investigated whether piceatannol inhibits Akt phosphorylation, as Akt is the main molecule upstream of NF- $\mathrm{KB}$ that has a significant role in cellular growth, adhesion and differentiation (28). Treatment with piceatannol completely suppressed Akt phosphorylation. This was further confirmed by conducting luciferase reporter assays and RT-PCR following treatment of the cells with an Akt inhibitor LY294002. Therefore, the NF- $\kappa B$-mediated Akt pathway revealed the absolute effects on TNF- $\alpha$-induced MMP-9-dependent invasion in this study.

The role of MAPKs in the regulation of MMP-9 expression is particularly well understood in TNF- $\alpha$-stimulated cancer cells (29-31). Previously, the regulation of TNF- $\alpha$-induced MMP-9 activity has been reported via ERK, p38 and JNK phosphorylation, whereas non-phosphorylated ERK, p38 and JNK kinase expression was unaffected (32). However, Lee et al have reported that TNF- $\alpha$-induced p38 is an effector MAPK that induces MMP-9 expression regardless of the activation of ERK1/2 and JNK (23). Therefore, additional studies are necessary to elucidate the precise signaling mechanism that controls NF- $\mathrm{KB}$ activity and its regulatory kinases during piceatannolinduced MMP-9 inhibition in DU145 prostate cells. 
In summary, the current study suggests that MMP-9 plays a considerable part in the regulation of MMP-9, resulting in an inhibition of invasion in DU145 prostate cancer cells. Finally, these results demonstrate that piceatannol is a potent inhibitor of TNF- $\alpha$-induced MMP-9 expression and invasion by suppressing the Akt-mediated NF- $\kappa \mathrm{B}$ pathway.

\section{Acknowledgements}

This study was supported by the Basic Science Research Program through the National Research Foundation of Korea (NRF) funded by the Ministry of Education, Science and Technology (grant no. NRF-2012R1A1B4000508), Republic of Korea.

\section{References}

1. Koutroulis I, Zarros A and Theocharis S: The role of matrix metalloproteinases in the pathophysiology and progression of human nervous system malignancies: a chance for the development of targeted therapeutic approaches? Expert Opin Ther Targets 12: 1577-1586, 2008.

2. Himelstein BP, Canete-Soler R, Bernhard EJ, Dilks DW and Muschel RJ: Metalloproteinases in tumor progression: the contribution of MMP-9. Invasion Metastasis 14: 246-258, 1994.

3. Zucker S and Vacirca J: Role of matrix metalloproteinases (MMPs) in colorectal cancer. Cancer Metastasis Rev 23: 101-117, 2004

4. Heo SJ, Park EJ, Lee KW and Jeon YJ: Antioxidant activities of enzymatic extracts from brown seaweeds. Bioresour Technol 96: $1613-1623,2005$

5. Khan MN, Choi JS, Lee MC, Kim E, Nam TJ, Fujii H and Hong YK: Anti-inflammatory activities of methanol extracts from various seaweed species. J Environ Biol 29: 465-469, 2008

6. Brehmer B, Biesterfeld S and Jakse G: Expression of matrix metalloproteinases (MMP-2 and -9) and their inhibitors (TIMP-1 and -2) in prostate cancer tissue. Prostate Cancer Prostatic Dis 6: 217-222, 2003

7. Dasgupta S, Srinidhi S and Vishwanatha JK: Oncogenic activation in prostate cancer progression and metastasis: Molecular insights and future challenges. J Carcinog 11: 4, 2012.

8. Yoshida S, Ono M, Shono T, Izumi H, Ishibashi T, Suzuki H and Kuwano M: Involvement of interleukin-8, vascular endothelial growth factor, and basic fibroblast growth factor in tumor necrosis factor alpha-dependent angiogenesis. Mol Cell Biol 17: 4015-4023, 1997.

9. Ohshima $\mathrm{H}$ and Bartsch $\mathrm{H}$ : Chronic infections and inflammatory processes as cancer risk factors: possible role of nitric oxide in carcinogenesis. Mutat Res 305: 253-264, 1994.

10. Pahl HL: Activators and target genes of Rel/NF-kappaB transcription factors. Oncogene 18: 6853-6866, 1999.

11. Palayoor ST, Youmell MY, Calderwood SK, Coleman CN and Price BD: Constitutive activation of IkappaB kinase alpha and NF-kappaB in prostate cancer cells is inhibited by ibuprofen. Oncogene 18: 7389-7394, 1999.

12. Lü L, Tang D, Wang L, Huang LQ, Jiang GS, Xiao XY and Zeng FQ: Gambogic acid inhibits TNF- $\alpha$-induced invasion of human prostate cancer PC3 cells in vitro through PI3K/Akt and NF- $\kappa B$ signaling pathways. Acta Pharmacol Sin 33: 531-541, 2012.

13. Roupe KA, Remsberg CM, Yanez JA and Davies NM: Pharmacometrics of stilbenes: segueing towards the clinic. Curr Clin Pharmacol 1: 81-101, 2006.

14. Kuo PL and Hsu YL: The grape and wine constituent piceatannol inhibits proliferation of human bladder cancer cells via blocking cell cycle progression and inducing Fas/membrane bound Fas ligand-mediated apoptosis pathway. Mol Nutr Food Res 52: 408-418, 2008.
15. Jin CY, Moon DO, Lee KJ, Kim MO, Lee JD, Choi YH, Park YM and Kim GY: Piceatannol attenuates lipopolysaccharide-induced NF-kappaB activation and NF-kappaB-related proinflammatory mediators in BV2 microglia. Pharmacol Res 54: 461-467, 2006.

16. Kang CH, Moon DO, Choi YH, Choi IW, Moon SK, Kim WJ and Kim GY: Piceatannol enhances TRAIL-induced apoptosis in human leukemia THP-1 cells through Sp1- and ERK-dependent DR5 up-regulation. Toxicol In Vitro 25: 605-612, 2011.

17. Dong Z, Bonfil RD, Chinni S, Deng X, Trindade JC, Bernardo M, Vaishampayan U, Che M, Sloane BF, Sheng S, Fridman R and Cher ML: Matrix metalloproteinase activity and osteoclasts in experimental prostate cancer bone metastasis tissue. Am J Pathol 166: 1173-1186, 2005

18. Curran S and Murray GL: Matrix metalloproteinases: molecular aspects of their roles in tumour invasion and metastasis. Eur J Cancer 36: 1621-1630, 2000.

19. John A and Tuszynski G: The role of matrix metalloproteinases in tumor angiogenesis and tumor metastasis. Pathol Oncol Res 7: 14-23, 2001.

20. Kong D, Li Y, Wang Z, Banerjee S and Sarkar FH: Inhibition of angiogenesis and invasion by 3,3'-diindolymethane is mediated by the nuclear factor-kappaB downstream target genes MMP-9 and UPA that regulated bioavailability of VEGF in prostate cancer. Cancer Res 67: 3310-3319, 2007.

21. Bhoopathi P, Chetty C, Kunigal S, Vanamala SK, Rao JS and Lakka SS: Blockade of tumor growth due to matrix metalloproteinase-9 inhibition is mediated by sequential activation of beta1-integrin, ERK, and NF-kappaB. J Biol Chem 283: 15451552,2008

22. Ganesan P, Matsubara K, Ohkubo T, Tanaka Y, Noda K, Sugawara T and Hirata T: Anti-angiogenic effect of siphonaxanthin from green alga, Codium fragile. Phytomedicine 17: 1140-1144, 2010

23. Lee SJ, Park SS, Lee US, Kim WJ and Moon SK: Signaling pathway for TNF- $\alpha$-induced MMP-9 expression: mediation through p38 MAP kinase, and inhibition by anti-cancer molecule magnolol in human urinary bladder cancer 5637 cells. Int Immunopharmacol 8: 1821-1826, 2008.

24. Genersch E, Hayess K, Neuenfeld Y and Haller H: Sustained ERK phosphorylation is necessary but not sufficient for MMP-9 regulation in endothelial cells: involvement of Ras-dependent and -independent pathways. J Cell Sci 23: 4319-4330, 2000.

25. Mimeault M and Batra SK: Potential applications of curcumin and its novel synthetic analogs and nanotechnology-based formulations in cancer prevention and therapy. Chin Med 6: 31, 2011.

26. Lin AW, Chang CC and Mccormick CC: Molecular cloning and expression of an avian macrophage nitric-oxide synthase cDNA and the analysis of the genomic 5'-flanking region. J Biol Chem 271: 11911-11919, 1996.

27. Ghosh S, May MJ and Kopp EB: NF-kappa B and Rel proteins: evolutionarily conserved mediators of immune responses. Annu Rev Immunol 16: 225-260, 1998

28. Carpenter CL and Cantley LC: Phosphoinositide kinases. Curr Opin Cell Biol 8: 153-158, 1996.

29. Olson CM, Hedrick MN, Izadi H, Bates TC, Olivera ER and Anguita J: p38 mitogen-activated protein kinase controls NF-kappaB transcriptional activation and tumor necrosis factor alpha production through RelA phosphorylation mediated by mitogen- and stress-activated protein kinase 1 in response to Borrelia burgdorferi antigens. Infect Immun 75: 270-277, 2007.

30. Roberts JR, Rowe PA and Demaine AG: Activation of NF-kappaB and MAP kinase cascades by hypothermic stress in endothelial cells. Cryobiology 44: 161-169, 2002.

31. Behera AK, Thorpe CM, Kidder JM, Smith W, Hildebrand E and Hu LT: Borrelia burgdorferi-induced expression of matrix metalloproteinases from human chondrocytes requires mitogen-activated protein kinase and Janus kinase/signal transducer and activator of transcription signaling pathways. Infect Immun 72: 2864-2871, 2004.

32. Jayasooriya RG, Choi YH, Moon SK, Kim WJ and Kim GY: Methanol extract of Hydroclathrus clathratus suppresses matrix metalloproteinase-9 in T24 bladder carcinoma cells by suppressing the NF- $\mathrm{B}$ and MAPK pathways. Oncol Rep 27: $541-546,2012$. 